\title{
ESTUDO BACTERIOLÓGICO DE INFECÇÕES PÓS CIRÚRGICAS NO HU/UFPb.: - Participação do Enfermeiro -
}

\author{
Iolanda Beserra da Costa Santos* \\ Lauro Santos Filho** \\ Maria Marta Vieira de Melo Lima*** \\ Maria das Neves Ribeiro dos Santos***
}

\begin{abstract}
RESUMO - Considerando a infecção de ferida cirúrgica como uma freqüente causa de infecção hospitalar, o presente estudo relata um levantamento feito a partir de 45 casos deste tipo de infecção no Hospital Universitário da UFPb, tendo como finalidade investigar o prolongamento do tempo de internação do paciente com infecção de ferida cirúrgica. Identificouse a etiologia bacteriana destas infecções, determinando-se também o padrão de sensibilidade aos antimicrobianos com finalidade de propor medidas de prevenção e controle destas infecções, com a participação efetiva do enfermeiro.
\end{abstract}

\begin{abstract}
Considering the surgical wound infection as a frequent cause of nosocomial infection, this study reports a sampling made from 45 cases of these infections at the University Hospital of UFPB, to investigate the prolonation of the internation time of the patients with infected surgical wounds. It was identified the bacterial etiology of these infections, and also determinated the drugs sensibility patterns to propose guidelines to prevention and control of these infections with effective participation of the nurse staff.
\end{abstract}

\section{INTRODUÇÃO}

As infecções hospitalares surgiram com os primeiros hospitais e muito antes das pesquisas de Pasteur e outros cientistas da época, os médicos já tinham conhecimento de que determinadas infecçōes se desenvolviam mais freqüentemente em hospitais do que na comunidade. Isto se dá pelo fato de existir reunião indiscriminada de enfermos em um ambiente fechado facilitando a disseminação de diversas doenças; além disso a introdução contínua de microorganismos patogênicos num hospital torna as possibilidades de contágio evidentemente maiores. (AL TEMEIER, 1979).

De acordo com o Ministério da Saúde, infecção hospitalar é qualquer infecção contraída após internação do paciente, que se manifesta durante sua permanência no hospital ou mesmo após alta, quando puder ser relacionada com a infecção. (MINISTÉRIO DA SAÚDE, 1985)

Infecções de ferida cirúrgica são a segunda causa mais freqüente de infecções hospitalares, ficando abaixo apenas das infecções urinárias (NEVES, et. alii, 1986), sendo causa importante no aumento de custos hospitalares, morbidade, problemas psicossociais e incapacitação em alguns casos e morte em outros.

Vale salientar que a freqüência e intensidade de cada complicação dependem muito do patógeno infectante e do local da ferida cirúrgica (BENNETT \& BRACHMAN, 1979), admitindo-se que a metade de todas as complicações pós operatórias sejam de ferida cirúrgica e que $50 \%$ destas complicações são de origem infecciosa.
Vários fatores contribuem para aumentar a incidência de infecções pós cirúrgicas, que podem estar relacionados com: condições prévias do paciente, área operatória, doenças pré-existente, diabetes, nefropatias, insuficiência cardíaca, desnutrição, obsidade, gravidez, defesas orgânicas alteradas, idade, técnicas cirúrgicas empregadas e uso de instrumentos como sondas, agulhas, cateteres e drenos, que ao serem introduzidos no organismo humano levam consigo germes localizados nas mucosas e na superfície da pele, podendo determinar infecções no paciente. (HUTZLER, 1973: FREIRE \& MARANGONI, 1986; ZANON, 1986).

Uma ferida é considerada infectada quando se evidencia uma coleção de pús, esvaziando-se expontaneamente ou através de uma drenagem cirúrgica. A simp tes presença de microrganismos não significa infeç̧ão, uma vez que os próprios mecanismos de defesa são capazes de eliminá-los e permitir uma cicatrização normal. (SIL VA, 1983)

A ferida cirúrgica pode ser considerada infectada se for drenado material purulento dela, com ou sem cultura positiva, independente do microrganismo infectante ser de origem endógena ou exógena. A infecção endógena é causada por componentes da própria flora normal do paciente, enquanto que as de origem exógena são provocadas por microrganismos provenientes de profissionais da área de saúde e seus auxiliares ou de outros pacientes. (NEVES, et alii, 1986)

As infecções hospitalares de maneira geral são decorrentes de três condições básicas: a) elevada contaminação microbiana, capaz de superar a resistência orgânica local e sistêmica do paciente; b) presença de

\footnotetext{
* Professora da Disciplina Enfermagem em Centro Ciñírgico. DEMCA/UFPb.

** Prof. Adjunto de Microbiologia da UFPb. Mestre em Microbiologia.

*** Estagiárias do Laboratório de Bacteriologia do NUMETROP/UFPb.
} 
nutrientes microbianos ou de condições para a sua produção a partir da decomposição dos tecidos operados; c) depressão da resistência local e sistêmica que permita as modificações ininterruptas dos microrganismos que invadiram a lesão. (ZANON et alii, 1975)

\section{Classificação e profilaxia das Infecções Cirúrgicas:}

Para uma melhor avaliação dos índices de infecção é importante considerar os diferentes tipos de cirurgia em relação ao seu potencial de contaminação, adotando-se o esquema modificado do Ministério da Saúde.

Cirurgia Limpa - são feridas operatórias não infectadas realizadas em tecidos estéreis, que não houve penetração nos tratos respiratório, digestivo e urinário, sem presença e inflamação e infrações de técnicas cirúrgica. Os microrganismos que causam infecção em cirurgias' limpas são próprios da microflora.da pele, e em menor freqüência de fontes exógenas.

Para reduzir os índices destas infecções se faz necessário orientar o paciente para internar-se apenas no dia da realização da cirurgia, ou na véspera do procedimento, para que não haja colonização do paciente com germes da ecologia hospitalar. Caso seja detectado lesões infectadas é recomendável o adiamento cirúrgico a não ser em casos indispensáveis.

Cirurgia Potencialmente Contaminada - é quando a flora bacteriana local é pouco numerosa e nenhuma evidência de infecção ou maiores alterações nas técnicas cirúrgicas empregadas, mesmo que tenha havido penetração na orofaringe, vagina e vias biliares, em ausência de bile infectada.

Devem ser consideradas pela equipe cirúrgica e de enfermagem, uma série de fatores importantes com relação ao preparo para cirurgias de colon ou reto, que exigem técnicas especiais de lavagem intestinal, controle nutricional, uso de antibióticos profiláticos e laxativos.

Cirurgia Contaminada - são aquelas realizadas em tecido colonizado por microflora abundante de difícil descontaminação ou que tenham ocorrido falhas técnicas grosseiras. Compreende os ferimentos traumáticos recentes (menos de 12 horas) e incisões que atingem inflamações agudas não purulentas (NEVES et alii, 1986). Os cuidados para esses casos são como os curativos cirúrgicos, que devem ser feitos com todo rigor da técnica asséptica, a higiene do próprio paciente, e isolamento especialmente aqueles casos cuja contaminação seja de origem cutânea.

Cirurgia Infectada ou Suja - são aquelas realizadas em quaisquer tecidos ou órgãos apresentando processo infeccioso e supuração local como contaminação fecal, tecido desvitalizado retido e coleção purulenta (BENNETT \& BRACHMAN, 1979); MINISTÉRIO DA SAÚDE, 1984; SIL VA et alii, 1985).

Como medidas preventivas para redução da infecção em cirurgia citaremos alguns procedimentos:

- limitação da área a ser tricotomizada;

- higiene rigorosa do paciente;

- escolha de um produto eficaz na antissepsia da área cirúrgica;

- evitar o uso de dreno através da incisão;

- observar os tipos de pacientes (idosos, obesos, desnutridos).

Esta classificação tem sido importante para prog- nosticar a relativa probabilidade que uma ferida tem para se tornar infectada. Portanto, quanto mais contaminada for a cirurgia, maior será o índice de infecção. Admitindo-se os seguintes valores: feridas a partir de cirurgias limpas têm de 1 a $5 \%$ de risco para adquirir infecção, potencialmente contaminadas de 8 a $11 \%$, contaminadas de 15 a $17 \%$ e infectadas acima de $27 \%$ (ALTEMEIER, 1979; SIMMONS, 1982; MINISTÉRIO DA SAÚDE, 1984).

Existe portanto uma grande relação entre a freqüência de infecção incisional e inoculação de bactérias. Portanto, quanto mais contaminada for a cirurgia, maior será o índice de infecção (CRUSE \& FOORD, 1980).

\section{OBJETIVOS}

- Investigar o tempo de permanência hospitalar dos pacientes com inf ecção de ferida cirúrgica;

- Identificar a etiologia bacteriana do processo inf eccioso;

- Determinar os padrões de sensibilidade às drogas das amostras bacterianas isoladas;

- Propor medidas de prevenção e contrd té das infecções pós-cirúrgicas a partir dos resultados obtidos neste estudo.

\section{JUSTIFICATIVA}

A prevenção e o controle das infecções pós-cirúrgicas é antes de mais nada uma questão de educação dos profissionais de saúde (ZANON et alii, 1986). A infecção hospitalar tem sido um assunto bastante discutido nos últimos anos, e tem despertado o interesse das autoridades assim como de todos os setores do hospital, principalmente nas clínicas cirúrgica e obstétrica.

A infecção cirúrgica constitui uma parcela significativa no levantamento 'geral de todas as infecções hospitalares, por serem complicações inerentes ao ato cirúrgico (FERRAZ, 1982). Outro fato importante a ser considerado é a própria falta de equilíbrio entre o hospedeiro e os microrganismos existentes no ambiente hospitalar, falhas técnicas e procedimentos inadequados na execução das atribuições de rotina.

Deste modo as infecções pós-cirúrgicas assumem diferentes características, prólongando o tempo de permanência do paciente, elevando os custos hospitalares e principalmente provocando as complicações mais variadas para o paciente, familiares e equipe de trabalho (BENNETT, 1979).

Para prevenir e controlar as inf ecções existe a necessidade da eficácia de programas de conscientização do pessoal de saúde, implementação da lavagem de mãos, desinfecção e esterilização de equipamentos e, sobretudo, os cuidados de higiene pessoal, sendo todos estes fatores imprescindíveis no controle das infecções hospitalares (CARDOSO, 1986).

Considerando todas as formas de prejuízo para ambas as partes, tanto para o paciente como para a instituição hospitalares, justifica-se a realização deste estudo.

\section{INTERVENCOÕES DE ENFERMAGEM NA PRE- VENÇÃO E CONTROLE DE INFECÇÕES PÓS- CIRÚRGICAS}

A maioria dos aspectos práticos do controle ou 
profilaxia das infecções hospitalares constitui uma função do serviço de enfermagem, e seu trabalho merece destaque especial dentro de qualquer programa, caracterizando-se pelo contato contínuo com o paciente.

A prevenção e controle de infecção é atualmente um componente essencial, não somente para o paciente ou administradores de hospital, mas para toda comunidade, portanto é necessário valorizar o trabalho que o enfermeiro executa como membro da equipe na comissão de controle de infecção hospitalar.

Entre as atribuições da comissão de controle mencionaremos algumas de responsabilidade do enfermeiro:

- Estabelecer vigilância sobre as técnicas e procedimentos de assepsia e antisepsia em todos os setores do hospital.

- Trabalhar em conjunto com a administração do hospital, farmácia e setor de compras para estruturar rotinas.

- Supervisionar o uso de produtos germicidas adquiridos.

- Supervisionar a realização de procedimentos invasivos como drenagens venosas, cateterismo vesical e instalação de sondas.

- Coordenar os programas educacionais elaborando rotinas por escrito, referentes aos isolamentos, desinf ecção e limpeza do hospital.

- Planejar e executa os procedimentos direta ou indiretamente relacionados com a assistência ao paciente no que se refere a processo infeccioso.

- Realizar a investigação, procurando determinar se a inf ecção é hospitalar ou comunitária, endógena ou exógena, local da infecção e o agente etiológico.

- Reciclar o pessoal de enfermagem, recém admitidos com relação às novas técnicas empregadas como meio de prevenir inf ecções.

- Colher material de incisões cirúrgicas para cultura, nos casos suspeitos de infecção (AL MEIDA \& CAVALCANTE, .1985; MOURA, 1986; SIL VA, C. M., 1985).

\section{METODOLOGIA}

$\mathrm{Na}$ realização deste estudo, procedeu-se um levantamento de 45 amostras clínicas colhidas a partir de secreção de ferida cirúrgica, abrangendo pacientes internados na clínica cirúrgica e obstétrica do Hospital Universitário de UFPb.

Todos os pacientes eram predominantemente adultos, de ambos os sexos. $\mathrm{O}$ estudo durou seis meses e na realização desta amostragem foi utilizado um formulário padrão com informações referentes ao paciente e sua cirurgia. (Anexo I)

Antes da coleta das amostras - foi feito a assepsia do local com solução antisséptica de uso na clínica, e durante a realização do curativo foram feitas as coletas de material, utilizando-se nesta etapa um procedimento padronizado de enfermagem.

As amostras foram obtidas com auxílio de um "swab" estéril, sendo o mesmo introduzido na incisão cirúrgica levemente com movimentos rotatórios, em seguida o material colhido era introduzido em um tubo contendo meio de transporte (Stuart/Merck), identificado previamente com o número do formulário e em seguida remetido ao laboratório para processamento.

As amostras clínicas chegadas ao laboratório fo- ram inoculada previamente em meio de enriquecimento (Brain Heart Infusion/Merck) e incubados a $37^{\circ} \mathrm{C}$ durante aproximadamente quatro horas, antes da inoculação dos meios de isolamento primário.

Após enriquecimento prévio as amostras foram semeadas nos meios de Agar Mueller- -1 linton (Merck) acrescido de 5\% de sangue de carneiro, Agar Eosin Methilene Blue (Merck) e Agar Manitol Salgado (Merck) e incubados a $37^{\circ} \mathrm{C}$ durante 18 a 24 horas. A partir do isolamento preliminar as bactérias foram identificadas conforme bateria padrão de provas adotadas com rotina de laboratório.

Os testes de sensibilidade às drogas foi realizado empregando-se a técnica de difusão com discos preconizada por Bauer e cols, utilizando-se discos da marca CECON contendo as seguintes drogas: Amicacina, Ampicilina, Cefalotina, Cefoxitina, Cloranfenicol, Carbenicilina, Ceftriaxona, Fosfomicina, Gentamicina, Oxacilina, Penicilina, Sisomicina, Sulfazotrim, Tetraciclina e Tobramicina.

Os dados de laboratório, assim como as informações levantadas a partir dos formulários padronizados que acompanhavam os exames foram computados e analisados em termos de números e percentuais, sendo então tabulados para apresentação dos resultados permitindo obter conclusões.

\section{RESULTADOS}

Os resultados foram analisados a partir de um total de 45 amostras clínicas colhidas de pacientes apresentado infecção de ferida cirúrgica, e os dados obtidos são apresentados em forma de tabelas com valores percentuais.

Tabela I

UNIDADES DE INTERNAÇĀO ONDE FORAM COLETADAS AS AMOSTRAS CLÍNICAS

\begin{tabular}{l|c|c}
\multicolumn{1}{c|}{ UNIDADES } & No & $\%$ \\
\hline Clínica Cirúrgica & 33 & 73,3 \\
Clínica Obstétrica & 12 & 26,7 \\
\hline Total & 45 & 100,0 \\
\hline
\end{tabular}

Observa-se na tabela acima que a maioria dos pacientes encontravam-se internados na clínica cirúrgica $33(73,3 \%)$, e um número menor foi proveniente da clínica obstétrica $12(26,7 \%)$.

Tabela II

DISTRIBUIÇÃO DOS PACIENTES

ESTUDADOS DE ACORDO COM O SEXO E IDADE

\begin{tabular}{c|c|c|c}
\hline FAIXA & \multicolumn{2}{|c|}{ SEXO } & \multirow{2}{*}{ SUBTOTAL } \\
\cline { 2 - 3 } ETÁRIA & Masculino & Feminino & \\
\hline $11-20$ & 03 & 03 & 06 \\
$21-30$ & 02 & 11 & 13 \\
$31-40$ & 01 & 06 & 07 \\
$41-50$ & 01 & 03 & 04 \\
51 & 06 & 09 & 15 \\
\hline TOTAL & 13 & 32 & 45 \\
\hline
\end{tabular}

Detectou-se uma predominância de pacientes do sexo feminino $32(71,1 \%)$, e uma maior proporção de pacientes na faixa etária acima de 51 anos $(33,3 \%)$. 
Tebela III

TIPOS DE CIRURGIA REALIZADA E TEMPO DE PERMANÊNCIA DOS

PACIENTES COM INFECÇÃO DE FERIDA CIRÚRGICA.

\begin{tabular}{|c|c|c|c|c|c|c|c|c|}
\hline \multirow{2}{*}{$\begin{array}{c}\text { Tipo } \\
\text { de } \\
\text { Cirurgia }\end{array}$} & \multicolumn{7}{|c|}{ Permanência (dias) } & \multirow{2}{*}{ Sub-Total } \\
\hline & 01-04 & $05-10$ & $11-20$ & $21-30$ & $31-40$ & $41-50$ & $51-60$ & \\
\hline Dissecção Venosa & - & - & 01 & - & 01 & - & - & 02 \\
\hline Colostomia & - & - & 01 & - & - & - & - & 01 \\
\hline Hernioplastia & - & 01 & 01 & 02 & & 01 & - & 05 \\
\hline Amputação & - & - & - & - & - & - & 02 & 02 \\
\hline Histerectomia & - & - & 02 & 01 & - & - & - & 03 \\
\hline Apendicectomia & - & 01 & $\tau$ & - & - & - & - & 01 \\
\hline Cesariana & - & - & 04 & 03 & 04 & 01 & - & 12 \\
\hline Laparotomia & - & 01 & 01 & 01 & - & - & - & 03 \\
\hline Colecistectomia & - & - & - & 01 & - & - & - & 01 \\
\hline Drenagem Abcesso & 01 & - & 01 & - & - & - & - & 02 \\
\hline Outros & 03 & - & 04 & 01 & 02 & 02 & 01 & 13 \\
\hline Total & 04 & 03 & 15 & 09 & 07 & 04 & 03 & 45 \\
\hline
\end{tabular}

Tabela IV

TIPOS BACTERIANOS ISOLADOS A PARTIR DE 45 CASOS DE INFECÇĀO PÓS-CIRÚRGICA.

\begin{tabular}{lcc}
\hline Bactérias & № & $\%$ \\
\hline S. aureus & 18 & 24,0 \\
Klebsiella sp. & 11 & 14,7 \\
Escherichia coli & 10 & 13,4 \\
S. epidermidis & 08 & 10,6 \\
Enterobacter sp. & 08 & 10,6 \\
Pseudomonas sp. & 07 & 9,4 \\
Proteus sp. & 06 & 8,0 \\
Steptococcus faecalis & 04 & 5,3 \\
Outros & 03 & 4,0 \\
\hline Total & 75 & $100,0 \%$ \\
\hline
\end{tabular}

Dentro da amostragem realizada a cirurgia mais freqüente foi a Cesariana $12(26,7 \%)$, enquanto o tempo de permanência mais observado nos casos analisados foi entre 11 e 20 dias, sendo detectados 15 pacientes que permaneceram internados durante este período, com uma percentagem de $33,3 \%$.

Foram detectados 38 casos positivos $(84,4 \%)$ e 07 casos negativos $(15,5 \%)$, com o isolamento de 75 tipos bacterianos distribuídos de acordo com a tabela acima. A bactéria mais prevalente foi o Staphylococcus aureus $(24,0 \%)$ e a menos isolada foi o Streptococcus faecalis $(5,3 \%)$, havendo no entanto uma evidente predominância de germes Gram negativos $(56,0 \%)$.

Tabela V

PADRĀO DE SENSIBILIDADE E RESISTÊNCIA DE 68 AMOSTRAS BACTERIANAS ISOLADAS DE SECREÇĀO DE FERIDA CIRÚRGICA.

\begin{tabular}{|c|c|c|c|c|}
\hline \multirow{2}{*}{ DROGAS USADAS } & \multicolumn{2}{|c|}{ SENSÍVEIS } & \multicolumn{2}{|c|}{ RESISTENTES } \\
\hline & № & $\%$ & № & $\%$ \\
\hline Amicacina & 47 & 69,1 & 21 & 30,9 \\
\hline Ceftriaxona & 46 & 67.6 & 22 & 32,4 \\
\hline Gentamicina & 45 & 66,2 & 23 & 33,8 \\
\hline Tobramicina & 39 & 57,3 & 29 & 42,7 \\
\hline Sisomicina & 37 & 54,4 & 31 & 45,6 \\
\hline Cefalotina & 36 & 53,0 & 32 & 47,0 \\
\hline Sulfazotrim & 31 & 45,6 & 37 & 54,4 \\
\hline Cloranfenicol & 29 & 42,6 & 39 & 57,4 \\
\hline Fosf omicina & 27 & 39,7 & 41 & 60,3 \\
\hline Cefoxitina & 23 & 33.9 & 45 & 66,1 \\
\hline Tetraciclina & 18 & 26.5 & 50 & 73,5 \\
\hline Oxacilina & 17 & 25,0 & 51 & 75,0 \\
\hline Carbenicilina & 14 & 20,6 & 54 & 79,4 \\
\hline Penicilina & 07 & 10,3 & 61 & 89,7 \\
\hline Ampicilina & 06 & 8,9 & 62 & 91,1 \\
\hline Médias & \multicolumn{2}{|c|}{$41,38 \%$} & \multicolumn{2}{|c|}{$58,62 \%$} \\
\hline
\end{tabular}


A partir dos testes de sensibilidade foram obtidos valores médios de $41,38 \%$ de sensibilidade e $58,63 \%$ de resistência. As drogas mais eficazes foram a Amicacina $(69,1 \%)$ e Ceftriaxona $(67,6 \%)$, e entre as menos eficazes destacam-se as penicilinas naturais e sintéticas, com uma eficácia de apenas $25,0 \%$ ou menos.

\section{DISCUSSÃO}

As infecções hospitalares causadas por microrganismos do meio foram substituídos por microorganismos patogênicos que habitam normalmente a pele e mucosa do homem. (ZANON, 1987).

A infecção cirúrgica constitui uma parcela significativa no total de todas as infecções hospitalares, sendo considerada a segunda principal causa destas infecções. (AL TEMEIER, 1979).

Por outro lado, o reconhecimento da existência de infecção hospitalar através de algum tipo de sistema de vigilância é a primeira etapa no desenvolvimento de um programa para controlar este importante problema (BENNETT \& BRACHMAN, 1975), admitindo-se que o estabelecimento de programas orientados para o registro e divulgação das taxas de infecção de ferida cirúrgica produzem uma redução significativa destas inf ecções (HALEY et alii, 1985).

O esforço para controlar as infecções de ferida cirúrgica tem sido direcionado primariamente para aquelas operações com baixa probabilidade da incisão ter sido contaminada, são as chamadas cirurgias limpas, que compreendem 50 a $70 \%$ de todas as operações (ALTEMEIER et alii, 1976).

O fator idade tem significativa importância, pudemos verificar também este problema, com uma propagação de $33,2 \%$ de pacientes acima de 51 anos apresentando uma freqüência acentuada dos casos.

Os microrganismos determinantes de infecção em cirurgias limpas são próprios da microflora da pele e, em menor freqüência, de fontes exógenas. Por outro lado, é notável a maior freqüência de inf ecção associada com a abertura do trato intestinal, fato decorrente da abundante microflora residente. Em nossa amostragem o tipo de cirurgia mais freqüente foi a cesariana com $26,7 \%$, por outro lado, o tempo de permanência mais observado ficou entre 11 e 20 dias com uma percentagem de $33,3 \%$.

A partir da década de 60 os bacilos Gram negativos passaram a ser isoladas com maior freqüência de casos de Infecção Hospitalar, permanecendo no entanto os Staphylococcus aureus como importante patógeno em hospitais (SUASSUNA, 1985).

A exemplo de trabalhos anteriores, a maioria dos isolamentos obtidos neste estudo correspondeu a bactérias Gram negativas, principalmente Klebsiella sp. e Escherichia coli, no entanto, o germe mais encontrado foi o Staphylococcus aureus $(24,0 \%)$ o que confirma alguns dados anteriores e classifica esta bactéria como pertencente à ecologia hospitalar (SIL VA et alii, 1983).

Das amostras de Staphylococcus aureus isoladas detectamos $38,9 \%$ de cepas resistentes a oxacilina, o que pode ser considerado um fato relevante considerando que a importância epidemiológica desses casos é amplamente reconhecida (SCHAEFLER et alii, 1984; THOMPSON et alii, 1982; CROSSLEY et alii, 1979).

A presença de bactérias com múltipla resistência aos antimicrobianos é comum no ambiente hospitalar, e a disseminação e ocasionais surtos de infecção por estes microrganismos é um fato elevada importância, neste estudo detectamos um nível de resistência média de $58,6 \%$ considerado alto para o quantitativo de amostras isoladas.

\section{CONCLUSÃO}

Diante do exposto podemos concluir que apesar de todas as medidas de prevenção e controle instituída pela CCIH um número de inf ecção da ferida cirúrgica ainda é muito elevado.

um fato que deve ser considerado é a localização topográfica da cirurgia, faixa etária como fator predisponente a infecção bem como tempo de permanência antes mesmo da realização de cirurgia.

Em hospital escola se torna difícil um controle mais rigoroso devido a grande rotatividade de todos os profissionais da área de saúde e a conscientização dos mesmos no cumprimento de normas e rotinas do serviço; outro fato de relevância é a grande quantidade de estudantes dificultado o cumprimento da assistência plane jada para o paciente.

As bactérias isoladas de pacientes hospitalizados em geral tem um padrão de resistência às drogas mais elevado, dificultando a sua terapêutica.

Para uma melhor prevenção e controle das infecções pós-cirúrgicas é necessário que o controle bacteriológico seja instituído como atividade de rotina em todos os casos e que ha ja um acompanhamento ambulatorial mesmo após alta hospitalar.

$\mathrm{O}$ enfermeiro como membro da comissão deve propor medidas de isolamento para o paciente, fazendo orientação da equipe de trabalho nas enfermarias e divulgando os resultados com percentuais dos casos de infecção para conhecimento de todos os profissionais envolvidos.

\section{REFERÊNCIAS BIBLIOGRÁFICAS}

1 ALMEIDA, L.M.Q. \& CAVALCANTE R.G. Atribuições do Serviço de Enfermagem na prevenção e controle de infecção hospitalar Rev. Paul. Enf. São Paulo 5(4):149-151, 1985.

2 ALTEMEIER W.A., et alii, eds. Manual on the control of infection in surgical patients. Philadelphia: Lippincott; 29-30, 1976.

3 ALTEMIEIER W.A. 1979. Surgical infections incisional wound in: BENNETT, J.V. and BRACHMAN, PS. Eds. Hospital Infections, Boston. Little, Brown and CO. 287-306, 1979.

4 BENNETT, J.V. \& BRACHMAN, P.S. Hospital Infections. Ed. Little, Brown and CO. Boston, 1979.

5 CARSOSO, C.L. Estudo da flora bacteriana de mãos de populaçōes intra e extra-hospitalar no Hospital Universitário da UFRJ. Instituto de Microbiologia da UFRJ. Tese de Doutoramento, 1986.

6 CENTER FOR DISEASE CONTROL. Guidelines for the prevention and control of nosocomial infections, CDCUS. Department of Health and Human Services, Atlanta, Ga. 1981 .

7 CRUSE, P.J.E. \& FOORD, R. Epidemiologia da Infecção das feridas. Estudo prospectivo de 10 anos de 62.939 
feridas. Clínicas Cirúrgicas da América. Vol. 60:27-40, 1980.

8 FERRAZ, Edmundo M. Manual de controle de infeç̧ão em cirurgia. EPU São Paulo, 1982.

9 FREIRE, Evandro C.S. \& MARANGONI. Mesa redonda: Infecçōes Cirúrgicas. Ars Curandi Hospitalar. Ano IV Vol. VI no 4, 1986.

10 HALLEY R.W.; et alii. The efficacy of infection surveillance and control programs in preventing nosocomial infections in VS hospitals. AMJ Epidemiol: 121:182-205, 1985.

11 HUTZLER, Rudolf. Fatores pré-disponentes de infecção hospitalar. Revista do Hospital das Clinicas. São Paulo, junho de 1973.

12 MINISTÉRIO DA SAÚDE. Manual de Controle e Infecção Hospitalar. Comissão de Controle de Infecção Hospitalar. Brasília. Centro de Documentação do Ministério da Saúde, 123 p. 1985.

13 Portaria no 196 de 24 de julho de 1984.

14 MOURA, M.L.P.A. Curso de Infecção Hospitalar. Roteiro de aula, Congresso Brasileiro de Enfermagem. Recife, 1985.

15 NEVES, Ma. Aparecida et alii. Técnicas de limpeza e desinfecção da sala de operação. Estudo da eficácia após cirurgia infectada. Ars Curandi Hospitalar. Ano IV, Vol. IV no 1. pág. 5-23, 1986.
16 SILVA, C.M. da. Atuação da enfermeira na Comissão de Controle de Infecção Hospitalar. Rev. Paul. Enfer. São Paulo, 5(4):154-155, 1985.

17 SILVA, Newton Neves da et alii. Manual sobre prevenção $e$ controle de infecção hospitalar organizado pela Comissão de infecção do hospital ERNESTO DORNELLES. Porto Alegre. Setembro de 1985

18 SILVA, N. Neves da et alii. Infecção Hospitalar, mensuração e controle em um hospital geral. R. AMRIGS, Porto Alegre, 27(2):133-51, abr./jun. 1983.

19 SIMMONS, P.B. CDC. Guideline for prevention of surgical wound infections. Infect control 3(suppl) 187-96, 1982.

20 SUASSUNA, I. Mecanismos e tendências atuais de resistência bacteriana aos antibióticos. Clínica Hospitalar, 1(4): 7-26, 1985.

21 ZANON, Uriel et alii. Controle de infecções hospitalares. RevistaPaulista de Hospitais. Agosto, 1975.

22 ZANON, Uriel et alii. "A explosão dos Estafilococos. A mudança ecológica dos Gran negativos e os patógenos exdrúxulos dos anos 80". Prática Hospitalar. Revista de Comunicação Médica Continuada. Ano 1, Volume 1. no 1 pág. 39-46, 1986.

23 ZANON, Uriel \& NEVES, Jaime - Infecções hospitalares: Prevenção, Diagnóstico e Tratamento. Ed. Médica e Científica Ltda. Rio de Janeiro, 1987.

\section{A REBEn MUDOU. PARTICIPE DESTA MUDANÇA. LEIA INSTRUÇÕES NO FINAL DESTE NÚMERO.}




\section{UNIVERSIDADE FEDERAL DA PARAÍBA}

HOSPITAL UNIVERSITÁRIO

FICHA DE CONTROLE DE INFECÇÃO PÓS-CIRÚRGICA

LABORATÓRIO DE BACTERIOLOGIA / NUMETROP

I. IDENTIFICAÇĀO:

NOME:

REG. № IDADE: SEXO:

DATA DE ADMISSÃO DATA DA ALTA

II. TIPO DE CIRURGIA REALIZADA:

CLÍNICA: DATA DA COLETA:

TOPOGRAFIA CIRÚRGICA:

PRODUTO USADO ANTES DA COLETA DO MATERIAL:

III. RESULTADOS DE LABORATÓRIO:

BACTÉRIAS ISOL ADAS: A)
B)
C)
D)

IV. TESTES DE SENSIBILIDADE ÀS DROGAS:

\begin{tabular}{|l|l|l|l|l|l|l|l|l|l|l|l|l|l|l|l|}
\hline DROGAS & AMI & AMP & CAR & CEF & CFO & CRO & CCO & FOS & GEN & OXA & PEN & SIS & SUT & TET & TOB \\
\hline A & & & & & & & & & & & & & & & \\
\hline B & & & & & & & & & & & & & & & \\
\hline C & & & & & & & & & & & & & & & \\
\hline D & & & & & & & & & & & & & & & \\
\hline
\end{tabular}

